\title{
BMJ Open Influenza and morbidity and mortality risk in patients in Mexico with systemic arterial hypertension alone or with comorbidities: a retrospective, observational, cross-sectional study from 2014 to 2020
}

Alejandrina Malacara-Villaseñor, ${ }^{1}$ Hermes Ilaraza-Lomeli, ${ }^{2}$ Roberto Tapia-Conyer, ${ }^{3}$ Elsa Sarti (i) ${ }^{1}$

To cite: Malacara-Villaseñor A Ilaraza-Lomeli H, TapiaConyer $\mathrm{R}$, et al. Influenza and morbidity and mortality risk in patients in Mexico with systemic arterial hypertension alone or with comorbidities: a retrospective, observational, cross-sectional study from 2014 to 2020. BMJ Open 2021;11:e057225. doi:10.1136/ bmjopen-2021-057225

- Prepublication history and additional supplemental material for this paper are available online. To view these files, please visit the journal online (http://dx.doi.org/10.1136/ bmjopen-2021-057225).

Received 08 September 2021 Accepted 18 November 202

Check for updates

(c) Author(s) (or their employer(s)) 2021. Re-use permitted under CC BY-NC. No commercial re-use. See rights and permissions. Published by BMJ.

For numbered affiliations see end of article.

Correspondence to

Dr Elsa Sarti;

elsa.sarti@sanofi.com

\section{ABSTRACT}

Objectives In Mexico, patients with systemic arterial hypertension (SAH) are excluded from the influenza vaccination programme despite their risk of cardiovascular events as influenza-related complications. We investigated the impact of influenza on morbidity and mortality in patients with SAH.

Design This was a retrospective cross-sectional study that analysed data from early 2014 to mid-2020.

Setting Data were obtained from the Influenza Epidemiological Surveillance System in Mexico database. Participants 32663 cases of influenza in people aged $\geq 20$ years with a confirmed case of influenza-like illness, severe respiratory infection and/or influenza death were investigated.

Primary and secondary outcome measures Influenza deaths, hospitalisation frequency and the impact on hospitalisation and/or death due to influenza by the SAH variate alone and in combination with diabetes, obesity, chronic obstructive pulmonary disease, cardiovascular disease and/or smoking, and by vaccination status were assessed.

Results The hospitalisation frequency increased with age. Notably, 46.0\% (15 033/32 663) of confirmed influenza cases had at least one comorbidity, with SAH (19.2\%; 6260/32 663) and obesity (18.7\%; 6106/32 663) being the most prevalent. Most confirmed SAH cases (80.8\%; $5057 / 6260$ ) were in those who had not been vaccinated against influenza. There were 3496 deaths due to influenza (mortality rate, $0.69 \times 100000$ inhabitants), with the highest rates seen in those aged $\geq 80$ years $(80-89$ years, $2.0 \%$; $\geq 90$ years, $3.6 \%$ ). The case fatality rate due to influenza and SAH was significantly higher than those due to influenza without SAH in those aged $<50$ years, but not in the other age groups (20-29 years, 9.8\%, $\mathrm{p}<0.0005 ; 30-39$ years, $8.2 \%, \mathrm{p}<0.035 ; 40-49$ years, $17.8 \%, p<0.0005$; vs $15.1 \%-20.0 \%, p=0.31-0.99$ for those aged $\geq 50$ years).

Conclusions Our findings support the need to include $\mathrm{SAH}$ in public policies of influenza vaccination as a secondary prevention measure to avoid fatal outcomes.
Strengths and limitations of this study

- Our study helped clarify the risk-benefit balance of excluding patients with systemic arterial hypertension (SAH) from the influenza vaccination programme in Mexico.

- This large-scale retrospective study included data of over 30000 influenza patients.

- We assessed the impact of SAH (among other comorbidities) on various outcomes related to influenza infection, such as death and hospitalisation frequency.

- The study was limited in that the database from which influenza morbidity data were obtained covers $<10 \%$ of the health units throughout Mexico.

- A further limitation was that vaccination history was obtained by questioning the patient, which is likely to be less reliable than official paper or electronic documentation.

\section{INTRODUCTION}

Influenza, which is caused by an RNA virus, is a public health problem affecting approximately $5 \%-10 \%$ of adults and $20 \%-30 \%$ of children worldwide, with 3-6million cases reported each year and more than 640000 deaths per year. ${ }^{12}$ Additionally, influenza has a great potential to cause respiratory disease pandemics. $^{34}$

Vaccination is one of the most cost-effective strategies for the prevention and control of many diseases. In the case of influenza, the implementation of vaccination campaigns worldwide has decreased mortality and morbidity. ${ }^{5}$ Currently, the vaccination policy offered in Mexico covers children $<5$ years old; adults $>60$ years of age; those aged 5-60 years with risk factors such as asthma, heart 
diseases, immunodeficiencies, haemoglobinopathies, asplenia, chronic kidney disease, diabetes, obesity and arthritis; and pregnant women and healthcare workers. ${ }^{67}$ However, it excludes people diagnosed with systemic arterial hypertension $(\mathrm{SAH})$, leaving patients with this chronic disease unprotected and at risk of having a cardiovascular disease (CVD) episode as a complication of influenza infection. ${ }^{89}$

During the last 20 years, SAH has been identified as one of the most important risk factors for morbidity and mortality globally. ${ }^{10}$ According to the 2018 Mexican National Health and Nutrition Survey (ENSANUT), the prevalence of SAH in the population aged 20 years and older is $18.4 \%$ (women, $20.9 \%$; men, $15.3 \%$ ), representing at least 15.2 million Mexican people. ${ }^{11}{ }^{12}$ Although few studies focused on SAH and the impact of influenza vaccination are published, ${ }^{13-16}$ the WHO recently recommended including patients with only $\mathrm{SAH}$ as a risk group to be vaccinated. ${ }^{17}$

Given that the prevalence of SAH in Mexico is steadily increasing, mainly in adults older than 20 years, ${ }^{11} 12$ and that SAH by itself is not considered a risk factor for access to influenza vaccination in accordance with the public health policy of Mexico, this study was designed to determine the risk for each of the usual influenza outcomes (outpatient illness, hospitalisation and/or death) in patients with SAH in Mexico.

\section{METHODS AND ANALYSIS}

\section{Study design and patients}

The present study was a retrospective cross-sectional study using data from the Influenza Epidemiological Surveillance System in Mexico (SISVER). As this was an observational study with a secondary data source, it was not considered research with risk per article 17 of the Regulations of the General Health Law in the Field of Health Research. $^{18}$

The SISVER sentinel surveillance system uses an influenza case definition as follows: (a) suspected cases include a clinical diagnosis of influenza-like illness (ILI) and/ or an epidemiological association and (b) confirmed cases are diagnosed by real-time quantitative RT-PCR (qRT-PCR). The system collects biological samples and exhaustive clinical and epidemiological information on $10 \%$ of ILI cases and $100 \%$ of severe acute respiratory infection (SARI) cases and deaths due to influenza that occur in Mexico. ${ }^{6}{ }^{19}$ The sampling strategy for deciding which of the $10 \%$ of ILI cases were collected and analysed is as follows: in each health unit from SISVER, samples were to be taken from the first suspected case and sent to the laboratory for confirmation. Samples were not collected for the following nine cases and the process was repeated for every 10 cases. ${ }^{6}{ }^{6}$ Regarding the information collected, if the case was ambulatory, the clinical information was collected through patient interview, but if it was an in-hospital case, it was collected from medical chart review. A case was considered an in-hospital case if the patient spent at least 24 hours in hospital. In cases where the patient died, the information was also collected from the death certificate.

In this retrospective cross-sectional study, the SISVER database (Oficio de transparencia DGE-DGAE de la Secretaría de Salud con número 005533 referente a la Solicitud 0001200189920 del 4 de junio de 2020; the database was provided via a disk for the purpose of analysis and is not publicly available) entries from 1 January 2014 to 15 May 2020 were included. The analysis included all records of patients $\geq 20$ years old who were diagnosed with a laboratory confirmed influenza infection of ILI or SARI by qRT-PCR and who requested medical attention. A case of death by influenza included any deceased patient with ILI or SARI, who had a positive laboratory result for influenza, and whose death certificate contained a diagnosis of influenza or pneumonia as the basic cause of death. If something other than influenza or pneumonia was listed as the basic cause of death on the death certificate, that individual was not considered to be a case of death by influenza and was excluded from the present study. All influenza deaths were rectified or ratified by an influenza-specific governmental scientific committee. Deaths ratified by this committee were included in the present study. ${ }^{19}$

\section{Outcomes and statistical analysis}

A descriptive analysis of the variables studied was performed, as well as bivariate and stratified (by age group) analyses considering the impact on hospitalisation and/or death due to influenza by the SAH variate alone and/or combined with diabetes, obesity, chronic obstructive pulmonary disease (COPD), CVD and/or smoking, and by influenza vaccination status. ORs were calculated considering the comparison between confirmed influenza cases with SAH alone or with other comorbidities, versus confirmed influenza cases without SAH, diabetes, obesity, COPD, CVD or a smoking habit. However, they could have diseases or lesions other than those listed. Statistical significance was determined using the $\chi^{2}$ test or Fisher's exact test. Incidence rates were estimated considering the total number of new confirmed influenza cases per 100000 inhabitants of each specific age group and totalled for persons-years of observation. Similarly, case fatality rates were determined by calculating the cases with influenza-related death over the confirmed cases per 100 inhabitants. Although the incidence rate calculations did not take into account the sampling scheme, the mortality and hospitalisation calculations took into account $100 \%$ of influenza cases reported in Mexico. For statistical analyses, Microsoft Excel (Microsoft Corp, Redmond, Washington, DC, USA), SPSS-PC (IBM, Armonk, New York, USA) and Epi Info software (Centers for Disease Control and Prevention, Atlanta, Georgia, USA) were used.

\section{Patient and public involvement}

Patients or the public were not involved in the design, conduct, or reporting or dissemination plans of our research. 


\section{RESULTS}

\section{Cases}

A total of 32663 confirmed cases of influenza were analysed; most of them were women $(56.0 \%$ (18 284/32 663) vs $44.0 \%$ (14379/32 663) men), the mean and median ages for women were 46 and 44 years, and for men, 47 and 46 years, respectively. The years $2014(21.1 \%, 6892 / 32663)$, $2016(21.9 \%, 7149 / 32$ 663) and 2017 (15.8\%, 5147/32 663 ) had the highest number of confirmed influenza cases, which corresponded to the seasons that also had the highest rates. ${ }^{20}$

The highest proportion of cumulative cases was in the group aged 30-39 years $(21.3 \%, 6952 / 32$ 663), followed by the group aged $40-49$ years $(20.8 \%, 6806 / 32663)$; however, the highest incidence rate per 100000 inhabitants corresponded to elderly patients, especially those aged $\geq 80$ years. Among all confirmed influenza cases, 19 948/32 $663(61.1 \%)$ were inpatient cases, and 12 $715 / 32663(38.9 \%)$ were outpatient cases. The highest proportion of hospitalised influenza cases was in patients aged $\geq 80$ years, with the frequency of hospitalisation increasing with age. For each outpatient case of influenza, 1.56 persons were hospitalised (online supplemental table S1).

Among all confirmed influenza cases, $46.0 \% \quad$ (15 $033 / 32663$ ) of patients had at least one comorbidity. SAH and obesity were the most prevalent, at $19.2 \%$ (6260/32 $663)$ and $18.7 \%(6106 / 32663)$, respectively, followed by type 2 diabetes $(17.7 \%, 5794 / 32663)$, smoking (11.4\%, $3711 / 32$ 663), COPD (6.5\%, 2136/32 663) and CVD $(4.9 \%, 1607 / 32663)$. When comorbidities were broken down by age group, the burden of influenza disease and obesity was notable mainly in those $<50$ years of age, and among those aged $\geq 50$ years, SAH and diabetes were more prevalent (figure 1). The combination of SAH with another comorbidity of interest was more frequent for diabetes $(8.8 \%, 2884 / 32663)$ and obesity $(6.6 \%$, 2143/32 663) and less frequent for COPD (2.8\%, 925/32 $663)$, smoking $(2.7 \%, 881 / 32$ 663) and CVD (2.4\%, 772/32 663).

Regarding the vaccination history against influenza, $80.8 \%$ of those with a confirmed case of SAH $(5057 / 6260)$ had not been vaccinated, and only $15.1 \%$ (944/6260) had been vaccinated. The percentages do not add up to $100 \%$ because the vaccination status was unknown for some patients.

\section{Deaths}

In total, 3496 deaths due to influenza (overall mortality rate of $0.69 \times 100000$ inhabitants) were reported, with the group aged $\geq 80$ years presenting the highest rates, followed by the group aged 60-69 years. Regarding case fatality rates, the overall rate was $10.7 \%$ (3496/32 663), with the group aged 60-69 years presenting the highest rate $(19.4 \%, 690 / 3562)$, even when compared with the group aged $\geq 90$ years $(17.1 \%, 72 / 421)$.

Similar trends were observed with the mortality rates of influenza and SAH, where the higher the age group, the higher the mortality rate; however, in the case of fatality due to influenza and $\mathrm{SAH}$, the groups aged $<50$ years had significantly higher rates in comparison with the same age groups but without $\mathrm{SAH}$, showing that having influenza with SAH leads to worse outcomes in specific age groups (table 1).

The influenza case fatality rates found in patients with SAH $(16.3 \%$; 1020/6260) increased when data were analysed by pairs of SAH plus other comorbidities such as diabetes $(19.5 \%$; $534 / 2741)$, obesity $(18.6 \% ; 385 / 2068)$,

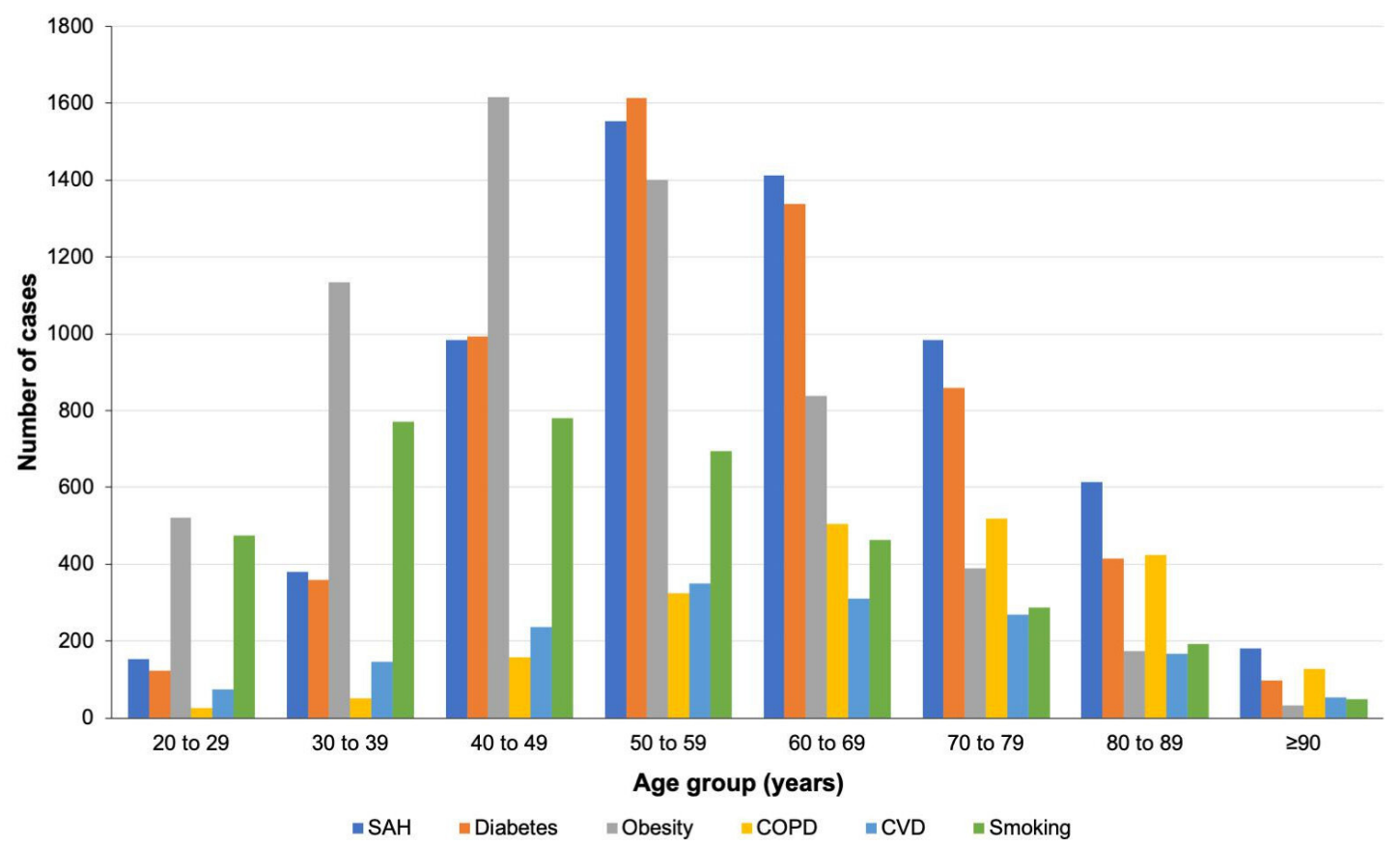

Figure 1 Cumulative influenza cases by age and comorbidity groups. COPD, chronic obstructive pulmonary disease; CVD, cardiovascular disease; $\mathrm{SAH}$, systemic arterial hypertension. 


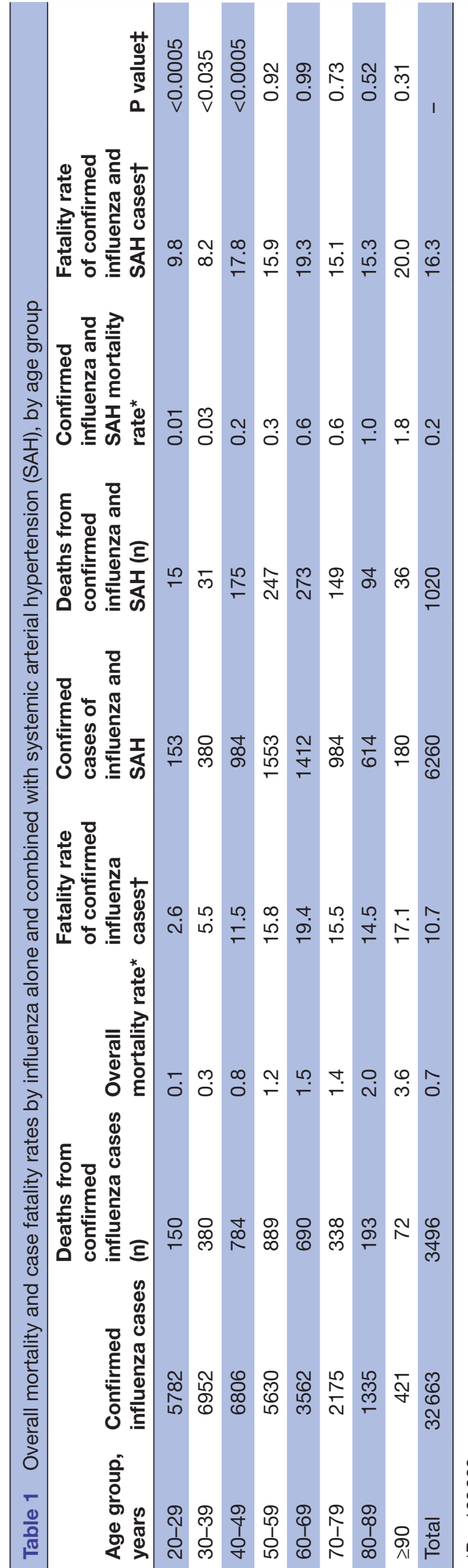

A
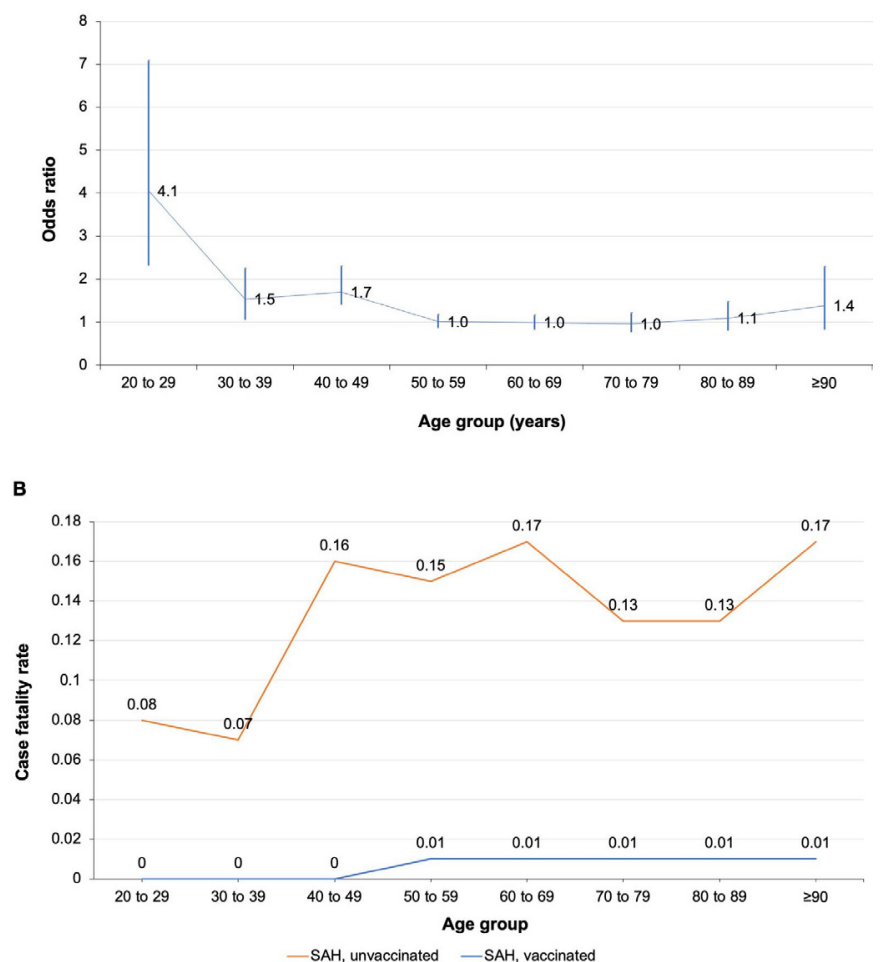

Figure 2 (A) ORs and Cls of case fatality rates by age group when compared between patients with and without $\mathrm{SAH}$ and $(\mathrm{B})$ influenza case fatality rates in patients with $\mathrm{SAH}$ according to their age group and vaccination status. Error bars show $95 \% \mathrm{Cls}$ in (A). SAH, systemic arterial hypertension.

CVD $(19.1 \% ; 138 / 721)$, COPD (16.8\%; 146/871) and smoking $(21.8 \% ; 185 / 849)$ (online supplemental table $\mathrm{S} 2$ ).

When observing the influenza case fatality rates with the presence of $\mathrm{SAH}$ alone (figure 2A) compared with those who died without a history of SAH, a clear impact of this morbid condition was observed in those aged $<50$ years (mainly in those aged 20-29 years), but not in those aged $\geq 50$ years, where it seems that the effect of age itself contributed to death.

When the analysis was performed considering the different SAH pairs, a greater risk effect was observed in the group of patients aged 30-39 years when combined with diabetes, obesity, COPD, CVD and smoking. Notably, in the combination of $\mathrm{SAH}$ with obesity, the greatest risk was found in the group aged 20-29 years (table 2).

Concerning vaccination history, age groups and the presence or absence of SAH, influenza-related deaths were notably lower among patients who were vaccinated $(<2 \%)$ compared with unvaccinated patients (range $7 \%-17 \%$ ) (figure 2B). Similar trends were observed in patients with SAH and other comorbidities.

The risk of hospitalisation (OR 3.3; 95\% CI 3.1 to 3.5; $\mathrm{p}<0.0001$ ) and death due to influenza (OR 1.9; $95 \%$ CI 1.8 to $2.1 ; \mathrm{p}<0.0001)$ was shown in patients with $\mathrm{SAH}$, and these risks increased more in the presence of other comorbidities (online supplemental table S2). The risks 


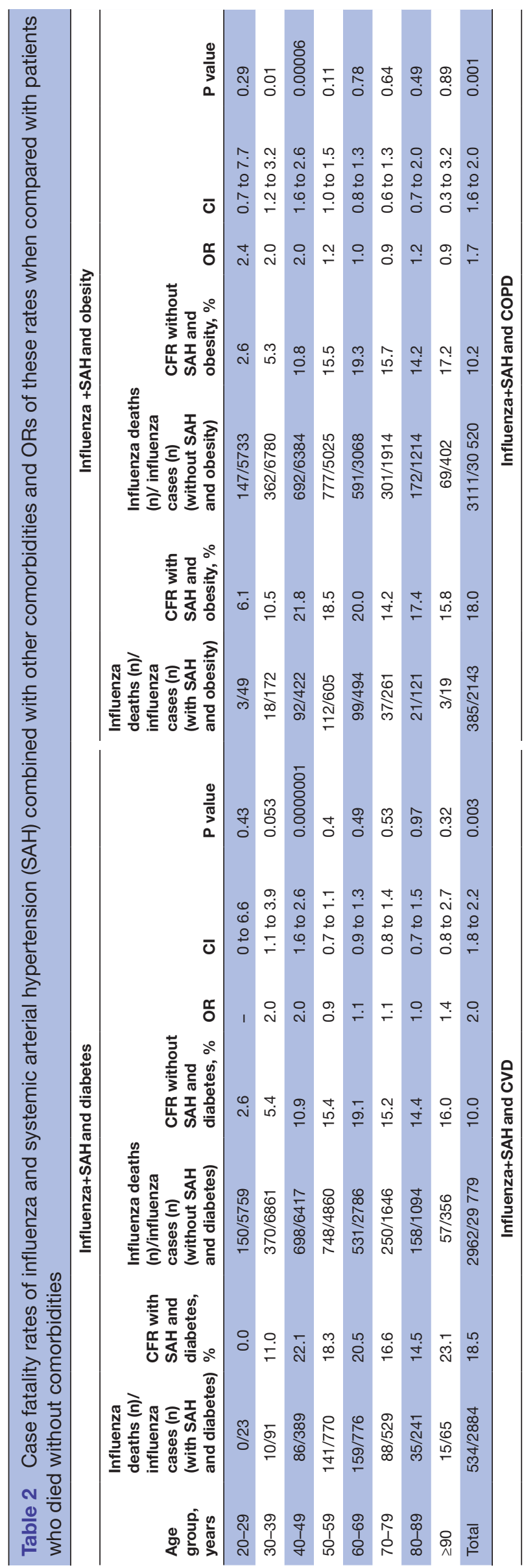

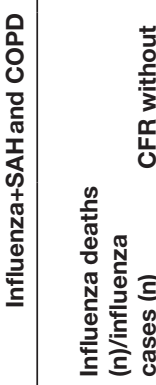

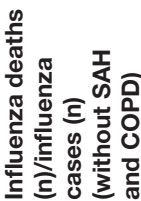

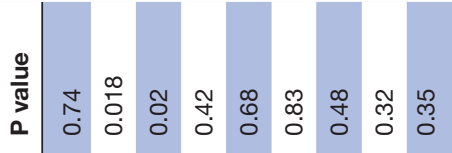

^.

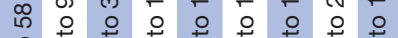

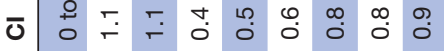

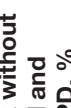

đ্র

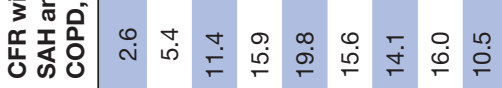

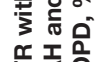

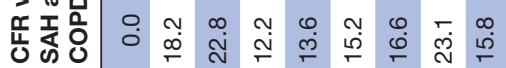

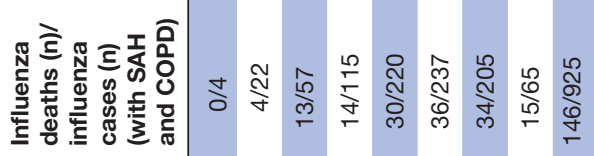

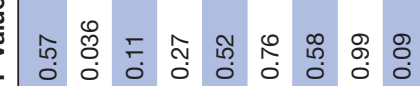

๑ $\stackrel{0}{0}$ の

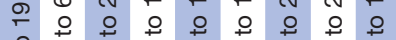

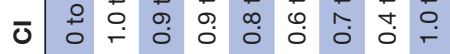

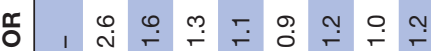

声

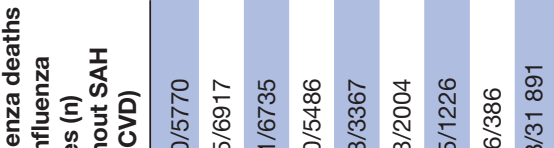

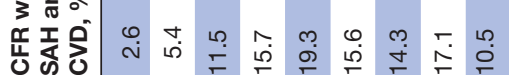

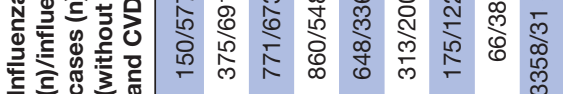

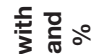

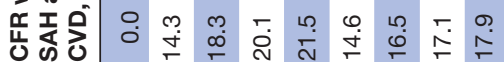

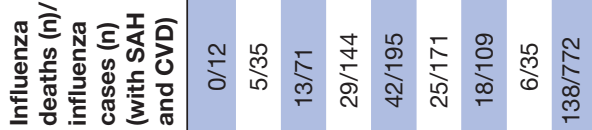

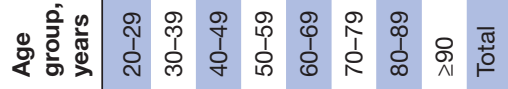

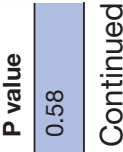

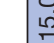

ธ

๙ั

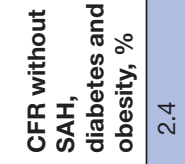

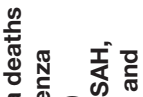

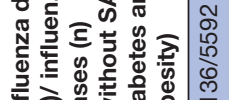

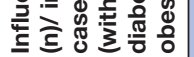

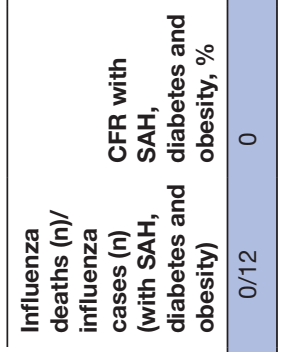

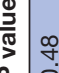

0 ०

0
$\infty$
$\infty$
0
0

ธ

뜽

亏ั

产

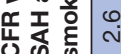

宽

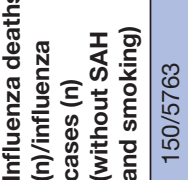

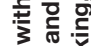

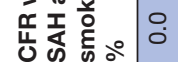

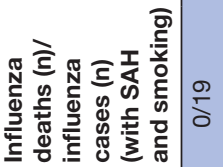

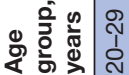




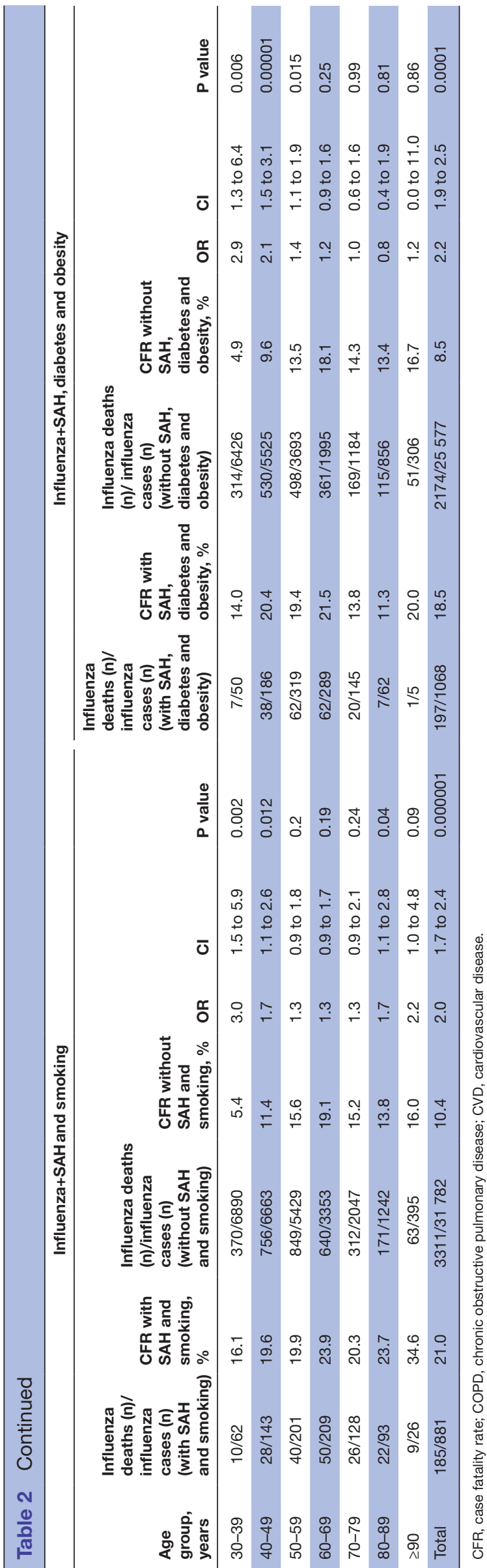

of hospitalisation and death due to influenza were also high among unvaccinated patients, and these risks further increased in the presence of other comorbidities (online supplemental table S3).

\section{DISCUSSION}

Several studies have investigated the impact of influenza and vaccination against influenza on morbidity and mortality in patients with comorbidities such as CVDs, diabetes, obesity, COPD and cerebrovascular disease, among others. ${ }^{6-9}$ However, few studies have been published regarding patients with only SAH and the impact of influenza vaccination. One Danish study showed that vaccination against influenza is associated with a reduction in the risk of all-cause mortality, cardiovascular mortality and myocardial infarction or stroke mortality in hypertensive patients without CVD. ${ }^{13} 14$ Nevertheless, this study did not compare this population with non-hypertensive patients, as all patients studied had SAH. Others have reported alterations in circulation in patients with influenza and patients with hypertension, ${ }^{815}$ and there is a high prevalence of hypertension $(63 \%)$ and mortality due to myocardial infarction and influenza. ${ }^{816}$ The present study is among the few in which an association was found that explains the impact of influenza on morbidity and mortality in patients having SAH only.

Regarding the cases of influenza and its epidemiological pattern, the present results are consistent with those reported by other authors: the greater the number of comorbidities, the greater the risk of hospitalisation and death from influenza, and the older the patient, the higher the incidence and hospitalisation rates. ${ }^{21-23}$ Notably, the absolute number of cases was higher in the group aged 30-50 years (working-age population) who become a source of contagion in their work environment; the negative economic impact that this can have has been previously reported. ${ }^{24}$ Regarding comorbidities, obesity and diabetes were the second and third most prevalent comorbidities in this study, after SAH. While a link between risk factors such as obesity, hypertension, diabetes and black/Hispanic ethnicity and the severity of influenza infection has been previously reported, ${ }^{25}{ }^{26}$ the presence of obesity has been suggested to be a possible confounding factor for these associations. ${ }^{27}$ The mechanism through which these four risk factors are associated with the severity of influenza infection is not yet fully understood.

In the present study, most of the patients with confirmed cases of influenza presented associated comorbidities, and $19.2 \%$ of the entire population evaluated, including patients $>20$ years of age, had SAH. This percentage is very similar to that published by the ENSANUT, ${ }^{11}$ which was $18.4 \%$ among a population $>20$ years of age. Therefore, despite the limitations of our study, we can infer that the results adequately reflect the situation in the country. 
Regarding influenza fatality, most publications report that the older the age, the higher the death rate. ${ }^{28-31}$ However, in our study, the group with the highest case fatality rate was the group aged 60-69 years, even when compared with the case fatality rate in the groups aged $\geq 70$ years. This supports the vaccination programme in Mexico where vaccination is offered free of charge to the whole population aged $>60$ years.

However, it is worth reflecting on other age groups. For instance, in the group aged 50-59 years, the case fatality rate was similar to that of the group aged 70-79 years and was even higher than that of the group aged 80-89 years. This has already been recognised by the Mexican health authorities, and even though the recommendation by the collegiate bodies on vaccination includes this group (in those $>50$ years old), ${ }^{7}$ the immunisation policy has yet to include this age group. A similar result was recently reported in a cross-sectional epidemiological study, in which the case fatality and mortality rate in this age group (50-59 years) was similar to that of patients $>60$ years old,$^{24}$ equivalent to an estimated range of $0.3-2.9$ million cases per year. The same study also reported that vaccination of this population is cost-effective; thus, implementing vaccination in this age group would be a necessary step.

People with a diagnosis of SAH alone are not considered as a vulnerable or at-risk population in the official guidelines. In the present study, the highest ORs were found in groups $<50$ years of age, mainly in the group aged 20-39 years, and these are groups that are not considered in the vaccination recommendations either because of their age or because of a comorbidity with hypertension. In the last national health survey of the country, ${ }^{12}$ it was reported that among adults aged 20-29 years, $5.6 \%$ had a previous diagnosis of SAH, in addition to $6.5 \%$ who were detected as hypertensive during the survey; in the group aged 30-39 years, these frequencies were $8.4 \%$ and $7.7 \%$, respectively, and in the group aged $40-49$ years, the frequencies increased to $16.8 \%$ for previous diagnosis and $12.1 \%$ by survey finding. Combining these results with our present findings, we found that $12.1 \%$ of those aged $20-29$ years, $16.1 \%$ of the group aged $30-39$ years and $28.9 \%$ of the group aged $40-49$ years had a mortality risk from influenza that was 1.7 to 4 times higher than that in the population without a comorbidity with SAH. The population with $\mathrm{SAH}$ is not recommended for vaccination in the current policy in Mexico, which would lead to an increase in the risk of hospitalisation and death from influenza in unvaccinated patients with SAH especially when other comorbidities are present.

Conversely, the effect of SAH in younger age groups was not observed in those aged 60-79 years where the highest overall fatality was observed. A possible explanation is that because this group of patients is known to be hypertensive, they were hospitalised earlier and received a more careful medical supervision, thus avoiding a fatal outcome. Of note, the official recommendations include this group among those recommended for vaccination.

It is essential to point out that hypertension alone is not the direct cause of death, but rather that influenza can lead to a cardiovascular event in a hypertensive patient. ${ }^{32-34}$ In this regard, there is evidence indicating that in patients with coronary artery disease, it is advisable to vaccinate against influenza since it is associated with a decrease in all-cause mortality. ${ }^{35}$ The same occurs with heart failure patients in whom this decrease in allcause mortality is also shown.

Overall, findings from this study support the need to apply the vaccine recommendation to those $>50$ years of age and to include populations with $\mathrm{SAH}^{17}$ in the influenza vaccination programme as a secondary prevention measure to avoid fatal outcomes. Specifically, we recommend the current guidelines be changed to replace 'Cardiovascular disease excluding SAH' with 'Cardiovascular disease including SAH' ${ }^{36}$ We expect that this new recommendation will benefit around 15 million people.

The present study has some limitations. Data for this study were obtained from a government database, and there are generally several limitations that must be considered for a correct interpretation of the results. For example, even though the results presented here give an epidemiological overview of the country, they do not represent the burden of disease (morbidity) because SISVER in Mexico operates under a sentinel model that covers less than $10 \%$ of the total number of health units in the country. This is not the case for deaths because according to official guidelines, $100 \%$ of influenza deaths should be reported to SISVER. Other possible reporting biases are related to vaccination history and comorbidities. Regarding the vaccination history, this is obtained by questioning the patient instead of via the submission of documents, so having an electronic vaccination system would objectively substantiate the vaccination status of any patient. As for the presence of comorbidities, this can be substantiated in inpatients, as opposed to outpatients, where it is only based on the information given by the patient. Additionally, we were not able to adjust for unknown potential risk factors because either the information was not requested from patients or may not have been listed in the clinical record and, as such, could not be reported in the database.

\section{CONCLUSIONS}

The present analysis of data from confirmed influenza cases collected by a sentinel system and $100 \%$ of deaths from influenza in Mexico during 2014 to week 20 of the year 2020 clearly shows the impact and risk that influenza has on morbidity, hospitalisation and death in patients with SAH (as the only comorbidity) as well as in those with SAH and other comorbidities. This publication adds value to the current literature in 
that the data show that having SAH might represent an additional risk for complications in patients infected with influenza, highlighting the need for this group of patients to be vaccinated to reduce the morbidity and mortality risks. Therefore, we recommend that patients with SAH be included in the national recommendations for vaccination against influenza, per 2020 WHO recommendations.

\section{Author affiliations}

${ }^{1}$ Departamento Medico, Sanofi Pasteur Mexico, Ciudad de Mexico, Mexico ${ }^{2}$ Rehabilitacion Cardiaca, Instituto Nacional de Cardiologia Ignacio Chavez, Ciudad de Mexico, Mexico

${ }^{3}$ Facultad de Medicina, Universidad Nacional Autonoma de Mexico, Ciudad de Mexico, Mexico

Acknowledgements The authors wish to thank Michelle Belanger, MD, of Edanz ( www.edanz.com), for providing editorial assistance, which was funded by Sanofi Pasteur México; Salma Pacheco, MD, for assisting with the first draft of the protocol and Rodrigo Saucedo, MD, for supporting us with the editorial reviews.

Contributors Conceptualisation, ES and AM-V; methodology, ES; validation, ES and AM-V; formal analysis, ES; writing — original draft preparation, ES; reviewing and correcting the draft manuscript, ES, AM-V, RT-C and HI-L; writing - review and final editing, ES, AM-V, RT-C and HI-L; supervision, ES; funding acquisition, AM-V.ES is responsible for the overall content as a guarantor. All authors have read and agreed to the published version of the manuscript.

Funding This research was funded by Sanofi Pasteur México (award/grant number is not applicable). The authors ES and AM-V are employees of Sanofi Pasteur México and had roles in conceptualisation of the study design, analysis and interpretation of the data, drafting the manuscript and reviewing the content for publication.

Competing interests ES and AM-V are employees of Sanofi Pasteur México. RT-C and $\mathrm{HI}-\mathrm{L}$ have no relevant conflicts of interest to report.

Patient consent for publication Not applicable.

Provenance and peer review Not commissioned; externally peer reviewed.

Data availability statement Data may be obtained from a third party and are not publicly available. All data relevant to the study are included in the article or uploaded as supplementary information. The data used in this study were obtained from the Mexican Ministry of Health and can be obtained from this source following a formal request: 'Oficio de transparencia DGE-DGAE de la Secretaría de Salud con número 005533 referente a la Solicitud 0001200189920 del 4 de junio de 2020'.

Supplemental material This content has been supplied by the author(s). It has not been vetted by BMJ Publishing Group Limited (BMJ) and may not have been peer-reviewed. Any opinions or recommendations discussed are solely those of the author(s) and are not endorsed by BMJ. BMJ disclaims all liability and responsibility arising from any reliance placed on the content. Where the content includes any translated material, BMJ does not warrant the accuracy and reliability of the translations (including but not limited to local regulations, clinical guidelines, terminology, drug names and drug dosages), and is not responsible for any error and/or omissions arising from translation and adaptation or otherwise.

Open access This is an open access article distributed in accordance with the Creative Commons Attribution Non Commercial (CC BY-NC 4.0) license, which permits others to distribute, remix, adapt, build upon this work non-commercially, and license their derivative works on different terms, provided the original work is properly cited, appropriate credit is given, any changes made indicated, and the use is non-commercial. See: http://creativecommons.org/licenses/by-nc/4.0/.

ORCID iD

Elsa Sarti http://orcid.org/0000-0003-3112-2679

\section{REFERENCES}

1 World Health Organization. Up to 650000 people die of respiratory diseases linked to seasonal flu each year, 2017. Available: https:// www.who.int/news/item/13-12-2017-up-to-650-000-people-die-of- respiratory-diseases-linked-to-seasonal-flu-each-year [Accessed 09 Aug 2021].

2 Iuliano AD, Roguski KM, Chang $\mathrm{HH}$, et al. Estimates of global seasonal influenza-associated respiratory mortality: a modelling study. Lancet 2018;391:1285-300.

3 European centre for disease prevention and control fact sheet for health professionals. Available: http://ecdc.europa.eu/en/ healthtopics/seasonal_influenza/basic_facts/Pages/factsheet professionals_seasonal_influenza.aspx [Accessed 09 Aug 2021].

4 Centers for Disease Control and Prevention. Pandemic influenza. Available: http://www.cdc.gov/flu/pandemic-resources/basics/pastpandemics.html [Accessed 09 Aug 2021].

5 Wang C-S, Wang S-T, Lai C-T, et al. Impact of influenza vaccination on major cause-specific mortality. Vaccine 2007;25:1196-203.

6 Gobierno de México, Secretaria de Salud, Dirección General de Epidemiología. Lineamiento estandarizado para La vigilancia epidemiológica Y POR laboratorio de la enfermedad respiratoria viral. Mayo del, 2021. Available: https://www.gob.mx/cms/uploads/ attachment/file/672708/Lineamiento_VE_y_Lab_Enf_Viral_20211008. pdf [Accessed 03 Dec 2021].

7 Centro Nacional para la Salud de la Infancia y Adolescencia. Vacuna Contra La influenza Estacional, 2015. Available: https://www.gob.mx/ salud/articulos/vacuna-contra-la-influenza-estacional [Accessed 09 Aug 2021].

8 Kjeldsen SE. Hypertension and cardiovascular risk: general aspects. Pharmacol Res 2018;129:95-9.

9 Maclntyre CR, Mahimbo A, Moa AM, et al. Influenza vaccine as a coronary intervention for prevention of myocardial infarction. Heart 2016;102:1953-6.

10 Kokubo Y, Matsumoto C. Hypertension is a risk factor for several types of heart disease: review of prospective studies. Adv Exp Med Biol 2017;956:419-26.

11 Campos-Nonato I, Hernández-Barrera L, Pedroza-Tobías A, et al. Hipertensión arterial en adultos mexicanos: prevalencia, diagnóstico Y tipo de tratamiento. Ensanut MC 2016. Salud Publica Mex 2018;60:233-43.

12 Shamah-Levy T, Vielma-Orozco E, Heredia-Hernández O. Encuesta Nacional de Salud Y Nutrición 2018-19, 2020. Resultados Nacionales. Instituto Nacional de Salud Publica. Available: https:// www.insp.mx/produccion-editorial/novedades-editoriales/ensanut2018-nacionales [Accessed 23 Aug 2021].

13 Modin D, Jørgensen ME, Gislason G. Influenza vaccine in heart failure: cumulative number of vaccinations, frequency, timing, and survival: a Danish nationwide cohort study. Circulation 2019;139:575-86.

14 Modin D, Claggett B, Joergensen ME, et al. The flu vaccine and mortality in hypertension. a Danish nationwide cohort study. Eur Heart J 2019;40:Abstract 1347.

15 Bogomolov BP, Deviatkin AV, Efimov LL, et al. [Microcirculation, hemostasis, and hemorheology in influenza and acute respiratory viral infections in patients with hypertension]. Ter Arkh 2001;73:7-11.

16 Yedlapati SH, Khan SU, Talluri S, et al. Effects of influenza vaccine on mortality and cardiovascular outcomes in patients with cardiovascular disease: a systematic review and meta-analysis. J Am Heart Assoc 2021;10:e019636.

17 World Health Organization. Who SAGE seasonal influenza vaccination recommendations during the COVID-19 pandemic. Available: https://www.who.int/immunization/policy/position_papers/ Interim_SAGE_influenza_vaccination_recommendations.pdf?ua=1 [Accessed 09 Aug 2021].

18 Diario Oficial de la Federación. Reglamento de la Ley General de Salud en Materia de Investigación para La Salud. Available: http:// www.diputados.gob.mx/LeyesBiblio/regley/Reg_LGS_MIS.pdf [Accessed 09 Aug 2021].

19 Instituto de Diagnóstico y Referencia Epidemiológicos "Dr. Manuel Martínez Báez". Lineamientos para La vigilancia POR laboratorio de la influenza Y otros virus respiratorios. INDRE. México: secretaría de salud, 2017. https://www.gob.mx/cms/uploads/attachment/file/ 647390/LVL Virus respiratorios.pdf

20 Dirección General de Epidemiología. Informe semanal de la temporada de influenza estacional 2019-2020 (semana 40 a la 20)/semana 52. Available: https://www.gob.mx/cms/uploads/ attachment/file/520496/20191226_archivo_INFLUENZA_SE52_2019. pdf [Accessed 09 Aug 2021].

21 Barnett K, Mercer SW, Norbury M, et al. Epidemiology of multimorbidity and implications for health care, research, and medical education: a cross-sectional study. Lancet 2012;380:37-43.

22 Müller L, Pawelec G. Aging and immunity - impact of behavioral intervention. Brain Behav Immun 2014;39:8-22. 
23 Centers for Disease Control and Prevention. Key facts about influenza (flu). Available: http://www.cdc.gov/flu/keyfacts.htm [Accessed 09 Aug 2021].

24 Betancourt-Cravioto M, Falcón-Lezama JA, Saucedo-Martínez R et al. Public health and economic benefits of influenza vaccination of the population aged 50 to 59 years without risk factors for influenza complications in Mexico: a cross-sectional epidemiological study. Vaccines 2021;9:188.

25 Dietz W, Santos-Burgoa C. Obesity and its implications for COVID-19 mortality. Obesity 2020;28:1005.

26 Schoen K, Horvat N, Guerreiro NFC, et al. Spectrum of clinical and radiographic findings in patients with diagnosis of $\mathrm{H} 1 \mathrm{~N} 1$ and correlation with clinical severity. BMC Infect Dis 2019;19:964.

27 Miyazawa D. Why obesity, hypertension, diabetes, and ethnicities are common risk factors for COVID-19 and H1N1 influenza infections. $J$ Med Virol 2021;93:127-8.

28 Centers for Disease Control and Prevention. Prevention and Control of Influenza Recommendations of the Immunization Practices Advisory Committee (ACIP). MMWR, 39, 1-15, 1990. Available: https://www.cdc.gov/mmwr/preview/mmwrhtml/00001644.htm [Accessed 09 Aug 2021].

29 Centers for Disease Control and Prevention. Flu \& people 65 years and older. Available: https://www.cdc.gov/flu/about/disease/65over. htm [Accessed 09 Aug 2021].
30 Centers for Disease Control and Prevention. Disease burden of influenza. Available: http://www.cdc.gov/flu/about/disease/us_flurelated_deaths.htm [Accessed 09 Aug 2021].

31 Centers for Disease Control and Prevention. Flu symptoms \& complications. Available: https://www.cdc.gov/flu/symptoms/ symptoms.htm [Accessed 09 Aug 2021].

32 Clar C, Oseni Z, Flowers N. Influenza vaccines for preventing cardiovascular disease. Cochrane Database Syst Rev 2015;5:CD005050.

33 Warren-Gash C, Smeeth L, Hayward AC. Influenza as a trigger for acute myocardial infarction or death from cardiovascular disease: a systematic review. Lancet Infect Dis 2009;9:601-10.

34 Udell JA, Zawi R, Bhatt DL, et al. Association between influenza vaccination and cardiovascular outcomes in high-risk patients: a meta-analysis. JAMA 2013;310:1711-20.

35 Rodrigues BS, Alves M, Duarte GS, et al. The impact of influenza vaccination in patients with cardiovascular disease: an overview of systematic reviews. Trends Cardiovasc Med 2021;31:315-20.

36 México Gde, Salud Sde. Lineamientos de vacunación para La temporada de influenza estacional 2021-2022, 2021. Available: https://www.gob.mx/salud/censia/documentos/lineamientos-devacunacion-para-la-temporada-de-influenza-estacional-2021-2022 [Accessed 3 Dec 2021]. 